\title{
Structural stability and microscale behaviors of the fortress wall from the sixth century Baekje Kingdom in ancient Korea
}

\author{
Jun Hyoung Park, Seok Tae Park and Chan Hee Lee*
}

\begin{abstract}
The Gongsanseong Fortress in Gongju, Republic of Korea, is one of the most essential remains for historical research of Baekje Kingdom, and reinforces on the fortress wall has continuously been implemented since the sixth century to present. Through visual inspections of the fortress ramparts, sections in which structural deformations have occurred, and then they were classified by morphological characteristics based on lithofacies that compose the ramparts, shape of each rock, and construction method. Also, automatic sensors that can measure behavior changes of the ramparts, and the surrounding environment were installed to monitor microscale movements of the ramparts and changes in the surrounding microclimate. As a result, damages were shown intensively on the ramparts that retain specific morphological characteristics, and it has been discovered that, even for the ramparts located in an identical environment, morphological characteristics affect damages and structural deformations of the ramparts because of behavior changes for minutes. Such changes in behavior can be classified based on reversibility and predictability, and different management schemes must be applied based on behavior change patterns. If we continuously operate and develop this monitoring system, it is expected to be meaningfully utilized in efficient maintenance of the cultural heritage of the ramparts.
\end{abstract}

Keywords: Gongsanseong fortress, Morphological characteristics of ramparts, Automated monitoring system, Behavioral monitoring, Environmental change

\section{Introduction}

The Baekje is an ancient kingdom located in the southwestern part of the Korean Peninsula from BC 18 to AD 660 , and its eras are divided on the basis of the location in the capital. The first capital city of Baekje was today's Seoul and, after the attack of the Goguryeo Kingdom in $\mathrm{AD} 475$, the kingdom relocated its capital to Gongju. Then, in AD 538, the capital was relocated again to Buyeo, and the 64-year period during which Gongju was the capital city is known as the "Woongjin Baekje Period". The heritage that represents this periods include the

${ }^{*}$ Correspondence: chanlee@kongju.ac.kr

Department of Cultural Heritage Conservation Sciences, Kongju National University, Gongju 32588, Republic of Korea
Gongsanseong Fortress and the Royal Tombs at Songsanri (Fig. 1).

The Gongsanseong Fortress, the subject of this research, is a fortress constructed to defend the Baekje's capital city and many cultural relics and remains that can help investigate Baekje's history more in depth were excavated through various surveys and researches. Also, after the fall of the Baekje, it was kept through different dynasties such as the Goryeo (AD 918 to 1392) and the Joseon (AD 1392 to 1910) Dynasty in ancient Korea to be utilized for military purposes. It is an important cultural heritage from which we can examine the culture, life and construction techniques of the Baekje. Also, it was registered as a UNESCO World Heritage as one of the Baekje Historic Areas in 2015.
Springer Open

(c) The Author(s) 2021. This article is licensed under a Creative Commons Attribution 4.0 International License, which permits use, sharing adaptation, distribution and reproduction in any medium or format, as long as you give appropriate credit to the original author(s) and the source, provide a link to the Creative Commons licence, and indicate if changes were made. The images or other third party material in this article are included in the article's Creative Commons licence, unless indicated otherwise in a credit line to the material. If material is not included in the article's Creative Commons licence and your intended use is not permitted by statutory regulation or exceeds the permitted use, you will need to obtain permission directly from the copyright holder. To view a copy of this licence, visit http://creativeco mmons.org/licenses/by/4.0/. The Creative Commons Public Domain Dedication waiver (http://creativecommons.org/publicdomain/ zero/1.0/) applies to the data made available in this article, unless otherwise stated in a credit line to the data. 


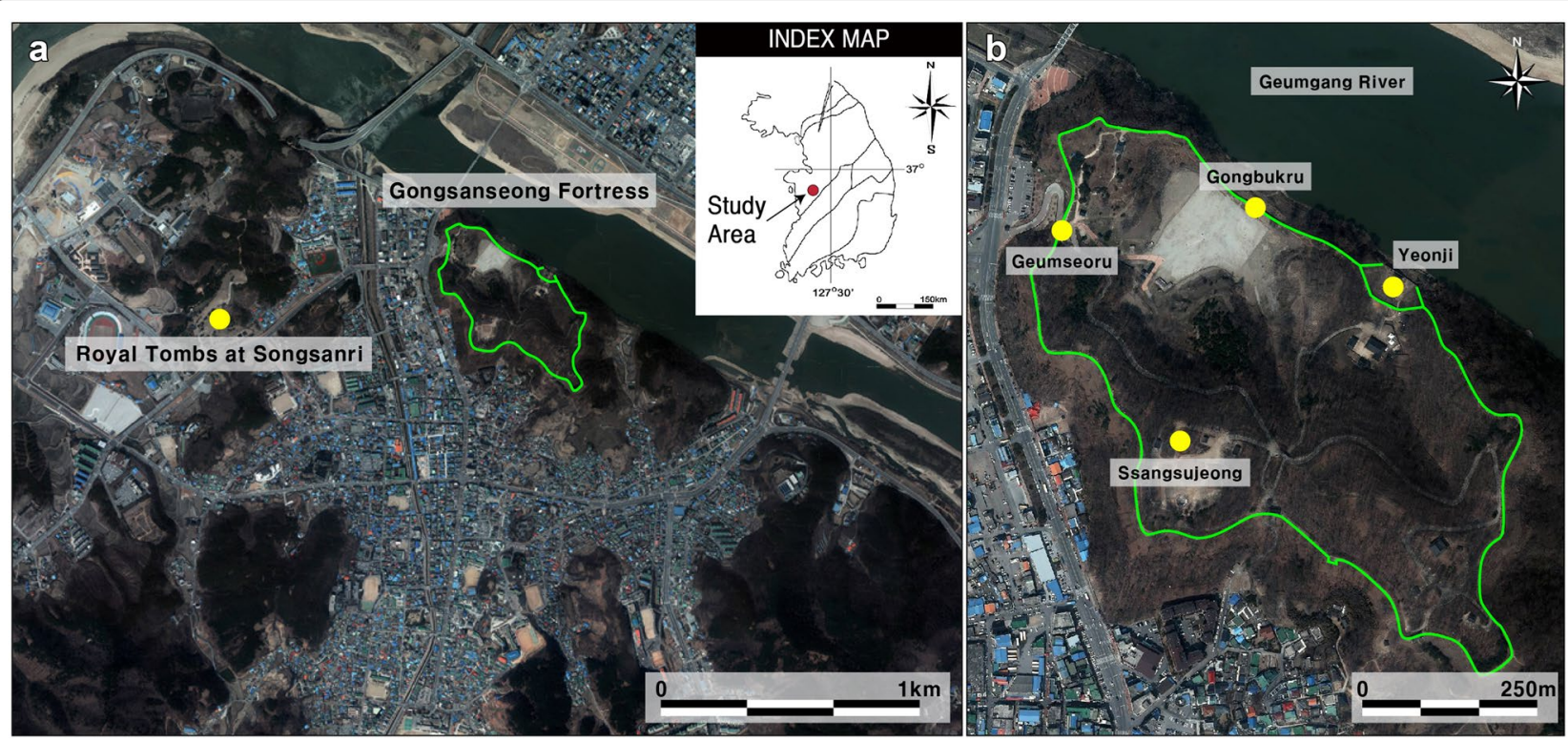

Fig. 1 Status of the study heritage. A Location of the Gongsanseong Fortress in Gongju. B Location of major construction in the Gongsanseong Fortress

Most of the early research on the Gongsanseong Fortress were conducted on archaeological details by Japanese scholars during the days of Japanese occupation (AD 1910 to 1945). Full-scale excavation surveys started in the 1980s after the liberation and verified the scale and construction technology of the ramparts and various facilities within the fortress. During this period, major reinforcements and repairs of the ramparts were performed in addition to the excavation efforts, which have led to its form we see today.

Though the ramparts were reinforced, structural deformations or partial collapses occurred on certain sections and, subsequently, questions were raised in regards to the stability of the ramparts as a whole. Especially after some parts of the ramparts collapsed in September 2013 due to localized heavy rain, scientific and engineering research officially began for the establishment of a system to conserve and manage of the Gongsanseong Fortress.

Because the fortress heritage boasts large scales among all architectural cultural properties, there are difficulties in simulating the stability of the entire section and analyses are performed with a focus on the ramparts where structural deformations are observed. An assessment on safety of the fortress and auxiliary facilities is performed through a multidirectional analysis by integrating research results from a variety of fields including geology, architectural engineering, geohydrology and conservation science $[1,2]$.

Also, in order to check if a structural deformation is in progress on the rampart, measuring sensors are installed to observe changes in slope or distance and, nowadays [3-9], the IoT technology is applied to construct a monitoring system capable of detecting changes in real-time [10-17].

For the conservation of cultural heritage, a variety of monitoring equipment is being used for various purposes, such as environmental measuring instruments, accelerometers, tiltmeters, and displacement meters. The monitoring equipment set up for the conservation of wall paintings in caves or tombs assesses the effects of the environment by measuring temperature and humidity [18-20], and accelerometers are used for checking the structure's natural frequency.

Tiltmeters and displacement meters are used to assess the movements of the structure and measure the changes in slope and distance of materials with sensors attached. In the study that monitored the Italian Leaning Tower of Pisa by installing measuring equipment, the study's researchers' interpretations were connected to changes in temperature, and the fact that the movements of England's Big Ben are affected by humanity's unnatural development activity was also discovered in this way [21-24].

The analysis was conducted on measured databases themselves on long-term accumulated measurement results to confirm repeatedly changing tendencies, and to further analyze the causes that affect this. There was substantial research on the methods of evaluating structural safety, and Structural Health Monitoring (SHM) is most widely used [25]. Analyzing the changes in structural movements using measuring sensors offers the 
advantage of being able to assess and predict the object's quantitative movements by utilizing simple equipment and devices.

However, most architectural cultural heritage sites use diverse materials, and the measured results are limited to the movements of the materials that have sensors attached to them. Thus, there can be a situation wherein the movements of the individual material cannot represent the entire structure itself, meaning that extra care should be given when selecting where to install the sensors.

In this research, the distribution of structural deformations occurred on the ramparts was examined and longitude and latitude coordinates were obtained by using a GNSS device. In addition, the ramparts were classified into different types based on construction materials, architectural techniques, and shaping of rocks, and a correlation has been found between the type of the rampart and the location at which a structural deformation occurred. Moreover, automatic precision measuring sensors were installed at points on the ramparts where structural deformations intensified in order to observe microscale movements in the incline of the ramparts and distance between the wall stones. At this time, environmental elements including the temperature, humidity, direction and speed of the wind near the ramparts were also measured to review what kind of effect such variables have on behavior changes of the ramparts.

\section{Study methods}

This study's researchers performed visual inspection to assess conservation status of Gongsanseong Fortress, selected damaged area, and established a monitoring system for rampart behavior. Various damages occurred on the ramparts were classified through visual inspection, and geographic information was acquired using GNSS equipment. The Gongsanseong Fortress is located in mountainous terrain, and the obtained geographic information was used to display the distribution of damaged ramparts on a satellite map. Also, a total of the 59 survey sections were set by combining the previous study and field investigation data. The material and morphological characteristics were identified for each section and the shape of each rock and the construction form of the ramparts were classified to identify the rampart morphological characteristics.

A behavior monitoring system was established for the damaged rampart where the deformation was relatively severe. Sensor selection was conducted by considering the resolution of measured data, the durability of sensors, and the practical economic feasibility, the result being the use of a conductive liquid form tiltmeter and a potentiometer displacement meter. tiltmeters (Jewell, 904-T high-gain version) and displacement meters (Novotechnik, TR-0050) were used to measure the microscale movements of the ramparts. The tiltmeter sensor has a spatial resolution of $0.005^{\circ}$, and a repeatability of $0.02^{\circ}$, while the displacement meter has a tolerance limit of $5 \mathrm{~mm}$ and a repeatability of $0.002 \mathrm{~mm}$. Protective gear with a size of $10 \mathrm{~cm}$ was installed for safely securing the sensors, and brackets were made according to the shape of the attachment location with the sensors being attached thereto.

The measurement cycle was set to a short time of several minutes in consideration of the aliasing of daily change, and solar cells and storage batteries were used for power supply. The measured data was stored in a data logger device (Campbell scientific, CR-1000) and transmitted to a server computer in the laboratory through a CDMA modem. In mountainous terrain, fading occurs during wireless communication, and the CDMA protocol, which makes fading correction easier than FDMA and TDMA methods, was applied to this study.

Finally, the measured data were transformed and processed to analyze the microscale behavior of the rampart according to the time series. In addition, the correlation was confirmed by comparison with the visual inspection data, and the factors influencing the change in the behavior of the ramparts were reviewed.

\section{Conservation status}

The first record on the reinforcement of the Gongsanseong Fortress can be found in a Korean history book called the Chronicles of the Three States, and the accounts stating that the fortress was repaired in $\mathrm{AD}$ 526 prove that the ramparts were built before this point in history. Although records on the reinforcement of the ramparts no longer remain in literature materials, the fortress of the periods of Unified Silla and Joseon Dynasty have been confirmed by archaeological discoveries on the ramparts and differences in the fortress construction technology, which reveals that collapses and reinforcements of the ramparts repeatedly took place for a long period of time. Full-scale reinforcement and repair of the fortress began in the 1960s, and records on the locations and details of reinforced sections remain relatively intact. Looking at these records for the locations of the ramparts where reinforcements took place, we can see that most of the ramparts have been reinforced.

Records of the collapse of the Gongsanseong fortress wall are confirmed in more than 6 instances but all of them have been completely reinforced today. Though the ramparts collapsed in a number of occasions, attempts to understand the status of damages on the ramparts were never made. In this research, visual inspections were conducted along the outer face of the Gongsanseong Fortress 
wall, and various damages and deformations created on the ramparts were discovered. A variety of damage types observed on the ramparts can be classified largely into damages on individual rocks and structural deformations on the ramparts.

Damage types on individual rocks are manifested in the form of cracks, protrusion and loss while structural deformations of the ramparts are further categorized into the structural relaxation, inflating phenomenon and unstable foundation (Fig. 2). Only a single type of damage may be observed on the fortress wall but, from time to time, a number of damage types occur complexly. Also, it is possible to observe damages on individual rocks without any structural deformation but, on the ramparts that have experienced a structural deformation, damages are often identified on individual rocks.

Results of inspections confirmed the 41 spots of the ramparts with damages and, in case several different types of damages are complexly observed in a single section, all of the types were recorded (Fig. 3). Looking at the types of damages that occurred on the fortress, damages on individual rocks are observed with any structural deformation on 7 spots. The 24 of the 34 sections where structural deformation spots occurred only displayed structural deformations without any damage on individual rocks and, at the remaining 10 spots, a variety of damage types were shown in a complex manner. Looking at the percentages of different damage types, inflating phenomenon and unstable foundation occurred at 24 (38.1\%) and $16(25.4 \%)$ spots, respectively, which tells us that structural deformations have happened on more than half of the ramparts (Fig. 4). Other damage types shown were losses at $12(19.0 \%)$, cracks at $5(7.9 \%)$, protrusion at $2(3.2 \%)$ and structural relaxation at $1(1.6 \%)$ spots, respectively.

Looking at the distribution of sections where damages occurred, we can see that 23 of the total 41 sports with damages are concentrated in the section between Geumseoru and Yeonji along the Geumgang River (Fig. 3). On the west and east sides, an extremely small number of sections have damages and, in contrast, damaged sections are shown to be concentrated on the ramparts near Ssangsujeong Pavilion on the south side. The root-cause investigation of the collapse of the ramparts reported that the incident was comprehensively affected by slopes of the surrounding topography, rampart construction techniques, surface water, underground water flows, conditions of the ground, and the distribution pattern of damages on the ramparts is also believed to have been influenced by such environmental factors [26, 27].

\section{Classification and morphological characteristics} Construction materials

The construction of the Gongsanseong Fortress used igneous, metamorphic and sedimentary rocks, which are further subdivided into over 10 different types of rocks.
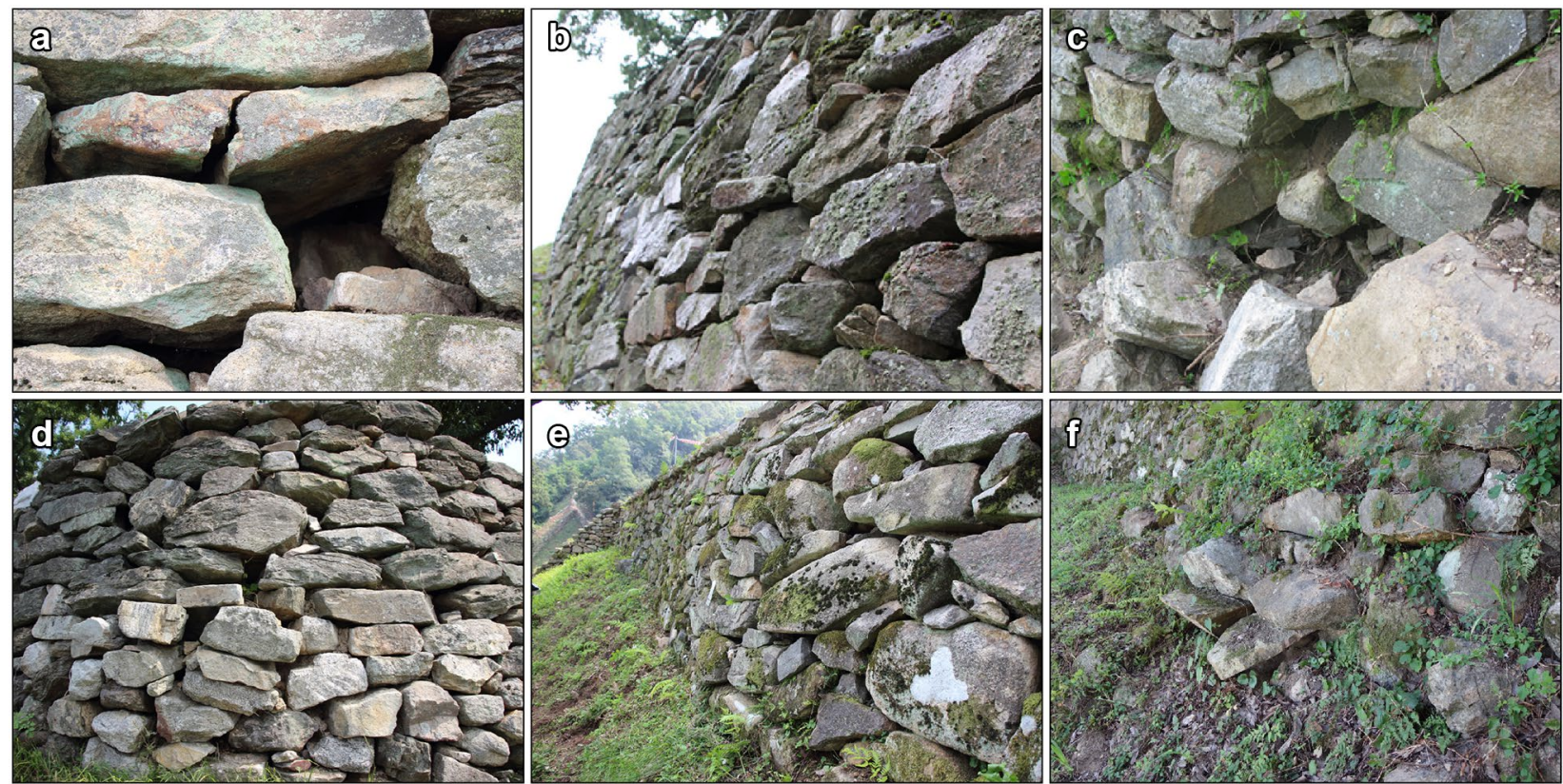

Fig. 2 Occurrences of representative deterioration status. A Crack. B Protrusion. C Loss. D Structural relaxation. E Inflating phenomenon. F Unstable foundation 


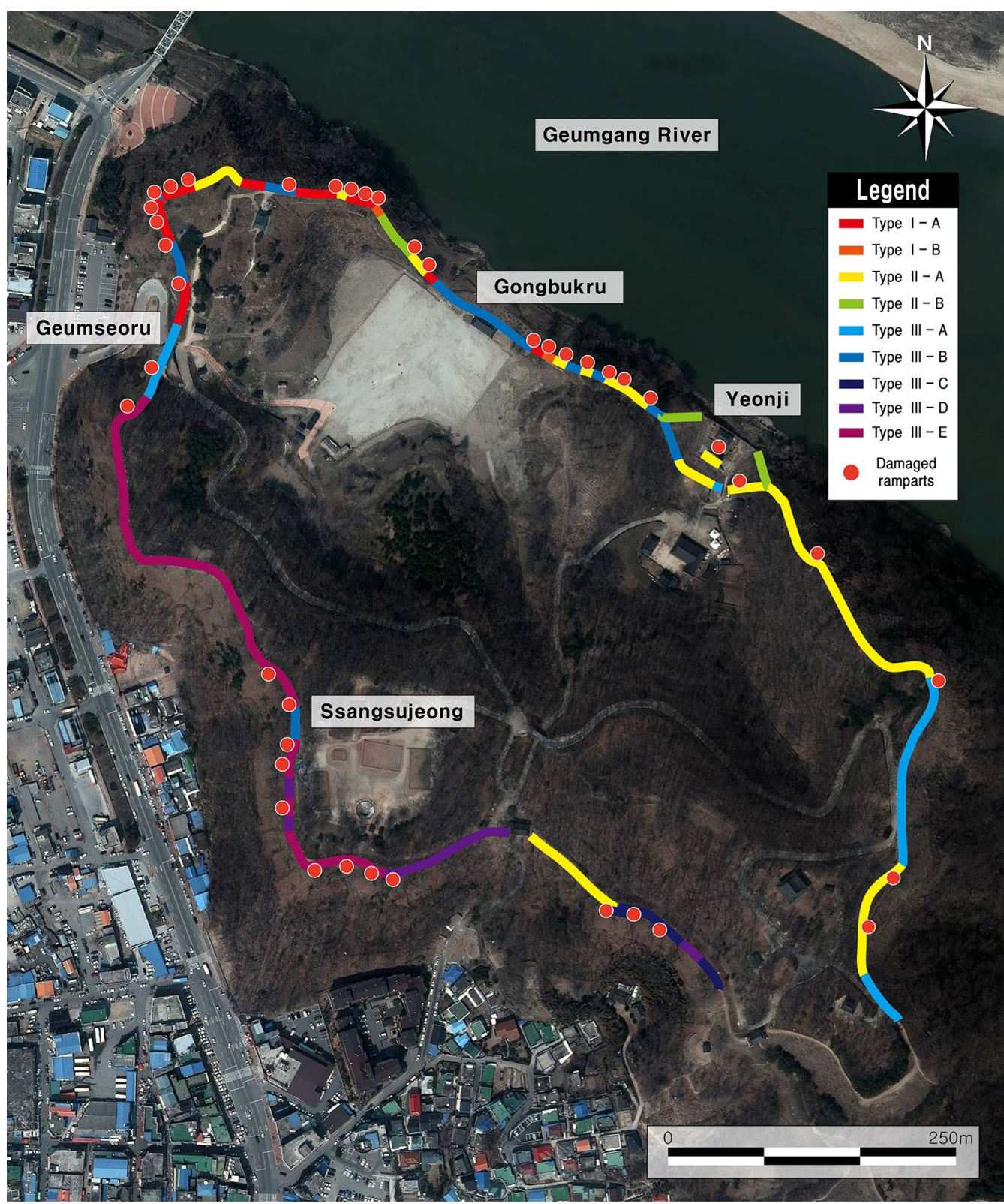

Fig. 3 Distribution map showing the 41 sections of representative damaged ramparts and the classified construction types of the fortress

Among them, gneiss and leucocratic granite are observed the most dominantly, and they show signs of quartzite and miscellaneous rock types mixed together (Fig. 5AC). Leucocratic granite was dominantly used on most of the ramparts while a great amount of gneiss is observed on northwest ramparts of the Gongsanseong Fortress from Geumseoru to Gongbukru.

The northwest ramparts of the Gongsanseong are a section where full-scale reinforcements and repairs were performed in the 1970s and we can see that the material primarily used to construct the ramparts during the period was gneiss. There are certain sections where miscellaneous rocks show over $70 \%$ share, and most of them are those that have been restored after the twentieth century by using sandstone and conglomerate. Quartzite is observed in nearly all ramparts but, as it has the form of filling stones inserted in between the rocks, exists in small sizes compared to other rocks.

Another construction material in addition to the rocks is internal fillers. Internal fillers refer to gravel, sand, clay and cement mortal used to fill the interior of the ramparts in order to help transfer loads, and, although only 


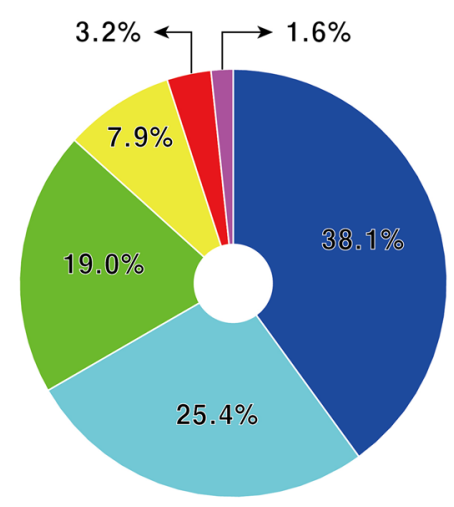

\begin{tabular}{|l|}
\hline Legend \\
\hline Crack \\
Protrusion \\
Loss \\
Structural \\
relaxation \\
Inflating \\
phenomenon \\
Unstable \\
foundation \\
\hline
\end{tabular}

Fig. 4 Shares as the deterioration types on the damaged ramparts

one of these materials is sometimes used for an application, a number of them are mixed together for use in other cases. An endoscope camera was utilized to find out the types of internal fillers of the Gongsanseong Fortress, and natural materials such as gravel, sand and clay were mainly identified (Fig. 5D, E). However, some of the restored sections were confirmed to have used cement mortar on the inside (Fig. 5F) and considering the differences in the type and mixture ratio of the aggregates depending on the location, it is understood that they were arbitrarily manufactured without any particular specification.

\section{Stone processing}

Stones that constitute of the Gongsanseong Fortress have different processed shapes depending on the location, and some of the sections used unprocessed stones. Also, it is possible to observe sections constructed by mixing original stones from the past and new stones processed when the ramparts were repaired after a collapse. Looking at the lengths of the stones, the horizontal lengths somewhat vary but the vertical lengths are mostly between 15 and $30 \mathrm{~cm}$. Stones are normally longer in the horizontal direction than the vertical direction, and they vary in size from square stones with the 1:1 ratio to rectangular rocks with the 1:4 ratio. Stones become smaller in the ramparts set up on a steep slope, which is presumed to be intentional in consideration of transport efficiency during the process of constructing the ramparts.

Different construction techniques are applied depending on the curves of the ramparts, angles of outer ramparts, construction methods, and the Gongsanseong Fortress shows clear discrepancies from one section to the next because of different construction methods. A construction method is based on continuity of joints and standardization of stones, and three construction techniques, which are straight stones piling; uneven stones layer piling; and uneven stones piling, are applied to the Gongsanseong Fortress. Straight rock piling is a technique in which rocks that are standardized and, thus, nearly uniform in size are built to fit the joints (Fig. 6A)
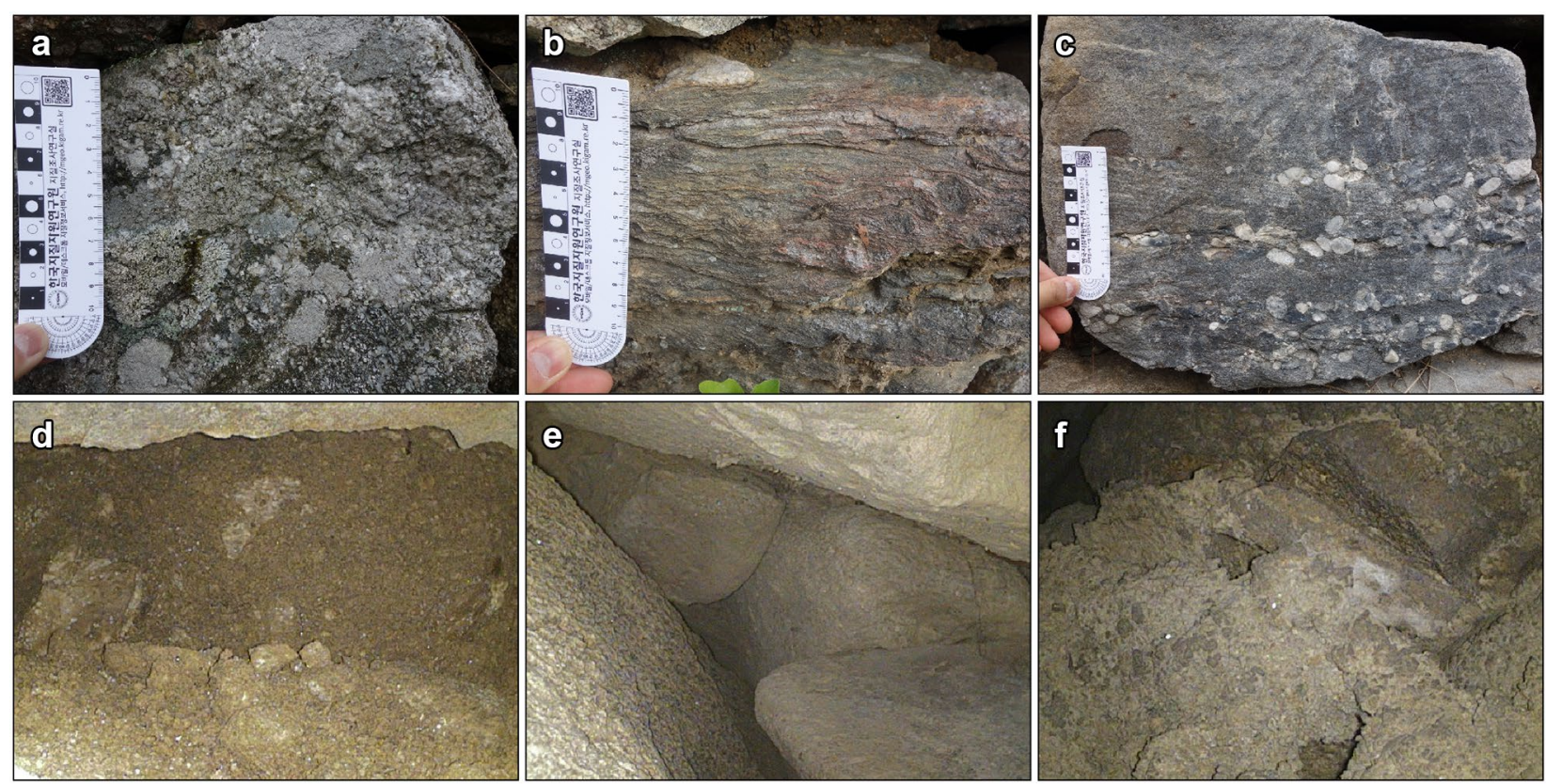

Fig. 5 Construction materials of the fortress wall. Rock properties origin as igneous (A), metamorphic $(\mathbf{B})$, sedimentary $(\mathbf{C})$ process, and internal fillers of sand (D), gravel (E) and cement mortal (F) 

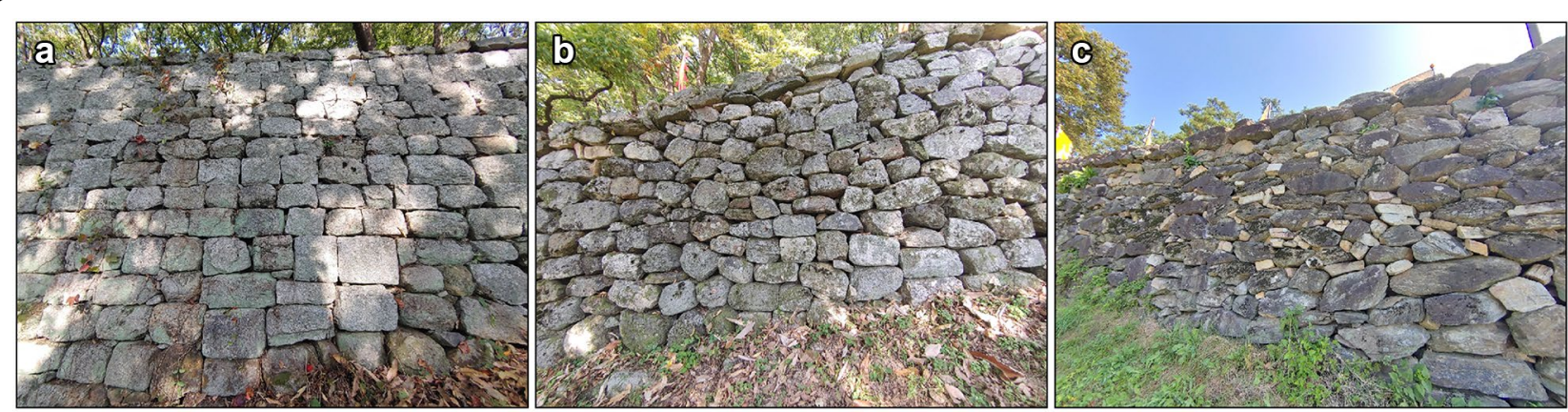

Fig. 6 Classification of the fortress walls through morphological characteristics. A Type of straight rock piling. B Type of uneven rocks layer piling. C Type of uneven rock piling

whereas uneven stones layer piling is a technique of constructing stones of atypical shapes in line with the joints (Fig. 6B).

Uneven stones piling is found in the ramparts to which no particular construction technique is applied and refers to the form in which stones of atypical shapes are piled up by simply matching the external surfaces (Fig. 6C). After classifying the ramparts based on the shapes of the stones and construction techniques, we were able to see that most of the Gongsanseong Fortress is built by the uneven stones layer piling method. Straight stones piling is applied mainly in restored sections while the section restored in the 1970s on the northwestern side of the fortress is mostly built by the uneven stones piling method.

\section{Construction types}

After comprehensively considering the materials used to construct the ramparts, shapes and construction techniques of the stones, we specified construction types to be able to group the ramparts that possess identical characteristics. Construction types are largely divided into Type I, II and III, and these can further subdivided into nine types (Table 1 and Fig. 3). Type I is the section using unprocessed stones and constructed by the uneven stones piling method. Gneiss was primarily used while certain sections used granite. Type II mainly used granite and applied the uneven stones layer piling method. Lastly, Type III was mostly constructed by the straight stones piling method and mainly applied igneous and sedimentary rocks. All of the ramparts that fall under Type III are those that were restored through reinforcements and repairs since the 1970s.

Looking at the locations for each type (Fig. 3), Type I is concentrated on the northwestern side of the Gongsanseong Fortress and shown to be distributed along the Geumgang River. Type II is observed on some parts of the northeastern and southern sides of the fortress and normally distributed along slopes. Type III has the
Table 1 Description of construction types for the fortress in this study

\begin{tabular}{|c|c|}
\hline $\begin{array}{l}\text { Construction } \\
\text { types }\end{array}$ & Descriptions \\
\hline \multicolumn{2}{|l|}{ Type I } \\
\hline I-A & $\begin{array}{l}\text { Uneven stones piling using the unprocessed stone } \\
\text { Having migmatitic gneiss construction parts over } 70 \% \\
\text { shares } \\
\text { Internal filling using natural materials } \\
\text { Using stones with } 18 \text { to } 26 \mathrm{~cm} \text { length and ratios in } 2.0 \\
\text { to } 2.6\end{array}$ \\
\hline I-B & $\begin{array}{l}\text { Uneven stones pilling using the unprocessed stone } \\
\text { Using leucocratic granite and aplite predominantly } \\
\text { Internal filling using natural materials }\end{array}$ \\
\hline \multicolumn{2}{|l|}{ Type ॥ } \\
\hline$\|-A$ & $\begin{array}{l}\text { Uneven stones layer piling mainly using leucocratic } \\
\text { granite } \\
\text { Variation in form and size as their location }\end{array}$ \\
\hline$\|-B$ & $\begin{array}{l}\text { Straight stones pilling using mixed rock with rectangular } \\
\text { shape } \\
\text { Variation rock type for construction as the location }\end{array}$ \\
\hline \multicolumn{2}{|l|}{ Type III } \\
\hline III-A & $\begin{array}{l}\text { Having sandstone construction parts over } 40 \% \text { shares } \\
\text { Two construction type of straight stones piling with } \\
\text { processed stone and uneven stones layer piling with } \\
\text { unprocessed stone }\end{array}$ \\
\hline III-B & $\begin{array}{l}\text { Using the processed stones with pinkish granite and } \\
\text { biotite granite and unprocessed stones which has } \\
\text { diverse rock type } \\
\text { Variation of construction type as the location }\end{array}$ \\
\hline III-C & $\begin{array}{l}\text { Straight stones piling using processed stone } \\
\text { Having granite construction parts over } 70 \% \text { shares } \\
\text { Internal filling with natural materials }\end{array}$ \\
\hline III-D & Internal filing with cement mortar \\
\hline III-E & $\begin{array}{l}\text { Uneven stones layer piling using mainly leucocratic } \\
\text { granite } \\
\text { Maintenance in } 1987\end{array}$ \\
\hline
\end{tabular}

highest share and is extensively distributed along the southern ridge of the Gongsanseong. Therefore, we can see that most of the Gongsanseong Fortress have been affected by repairs and reinforcements and the ramparts 
with no such records remaining are mostly located along the Geumgang river to the north of the fortress.

\section{Behavior monitoring}

\section{Automatic monitoring system}

The variety of damages exist on the ramparts, and structural deformations are observed throughout the Gongsanseong Fortress. In order to quantitatively detect and analyze such changes monitoring devices must be utilized to measure the changes in physical quantity. The types of a physical quantity that can be obtained through measurements are deformation, displacement, slope, load, pressure, velocity and acceleration, and a suitable sensing element needs to be used for the physical quantity we want to measure. In this research, potentiometertype displacement sensors and conductive liquid-type clinometer sensors were attached to check the movement and behavior changes of the ramparts.

These sensors were installed at 20 locations with high degrees of risk among the points where structural deformations, confirmed through visual inspections, have occurred. After projecting the original forms prior to the occurrence of structural deformations and considering the progress until now, we selected locations where we believed changes in physical quantity would manifest the most definitely and attached measuring sensors. We also installed environment monitoring devices in order to measure the changes in microclimate such as the temperature, humidity, rainfall, direction and speed of the wind in the area surrounding the Gongsanseong Fortress (Fig. 7).
The monitoring system consists of sensors that measure changes in the ramparts and a data logger that stores the measured values and sends them via communication. First, considering the fortress' locational characteristics, it is difficult to supply electricity so solar panels were installed, also, storage batteries were utilized to supply electricity to the sensors both during the day and at night. Structural changes of the ramparts affect the physical quantities measured by the sensors, which detect such changes by differences in electrical signals.

The data is then stored in the logger as digital signals, and a wireless communication device is utilized to send the data to the server computer in the lab. Once the data in the digital format is enabled to infer the form of the analog signal through the process of inverse transformation, we can visually check the behavior of the ramparts easily. Several sensors can be connected to a logger but, because the direct connection with the sensors must be formed by cables, 4 locations were designated considering the distribution of damaged sections in the Gongsanseong Fortress to establish the monitoring system. The measurement cycle of individual sensors was set as minimum of $10 \mathrm{~min}$ and maximum of $30 \mathrm{~min}$.

\section{Daily behavior}

Through the measuring sensors installed on the Gongsanseong Fortress, daily changes of the behavior were examined in comparison to the changes in temperature and, in order to minimize the effect of the amount of sunshine. We used measurement results from spring and fall, two seasons with identical lengths of day and night (Fig. 8) and (Table 2 and Fig. 9). Looking at the

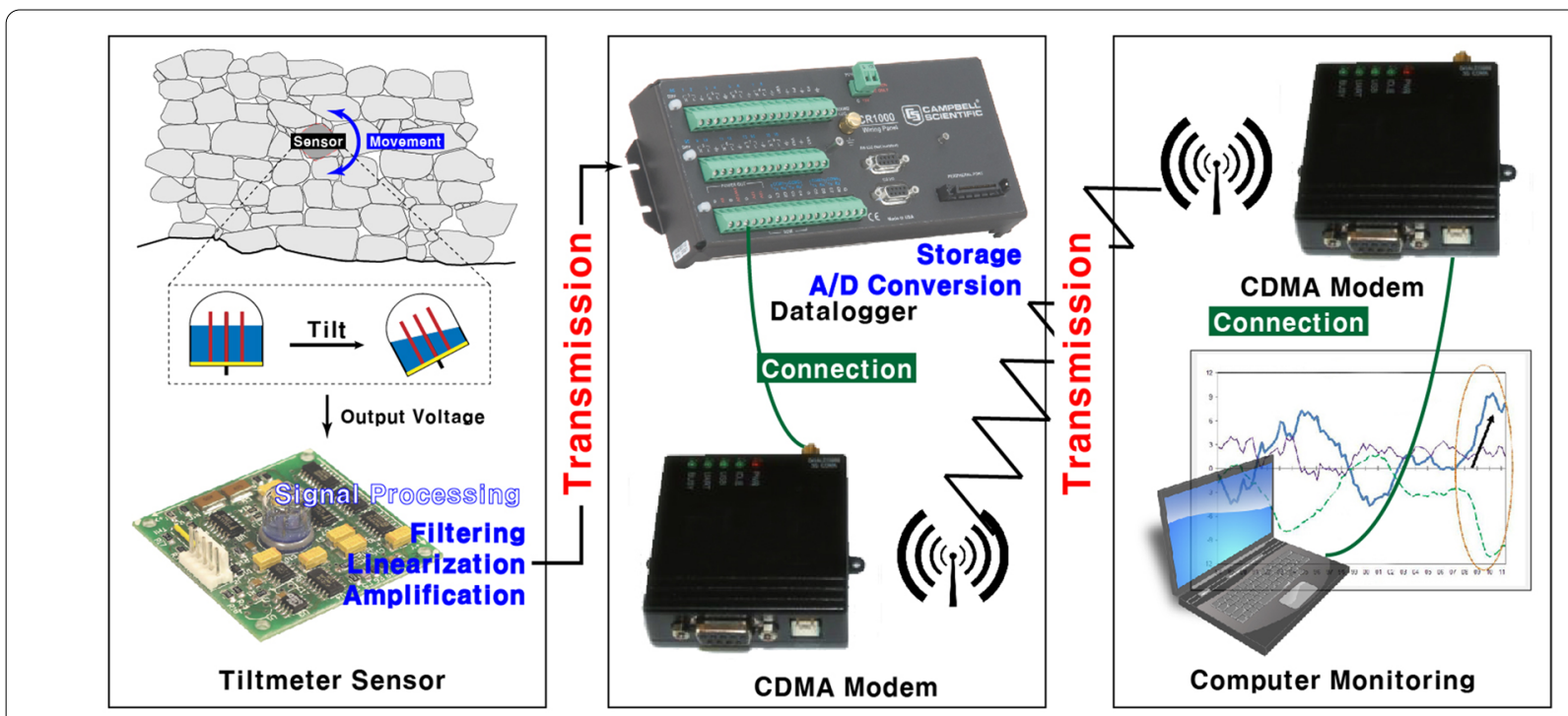

Fig. 7 Schematic photographs showing the monitoring system in this study 
Table 2 Tilt and temperature measurement result according to the time series of autumnal equinox

\begin{tabular}{lrrlllllllll}
\hline Time & X-axis $\left({ }^{\circ}\right)$ & Y-axis $\left({ }^{\circ}\right)$ & Temp. $\left({ }^{\circ} \mathbf{C}\right)$ & Time & X-axis $\left({ }^{\circ}\right)$ & Y-axis $\left({ }^{\circ}\right)$ & Temp. $\left({ }^{\circ} \mathbf{C}\right)$ & Time & X-axis $\left({ }^{\circ}\right)$ & Y-axis $\left({ }^{\circ}\right)$ & Temp. $\left({ }^{\circ} \mathbf{C}\right)$ \\
\hline $0: 00$ & 0.00000 & 0.00000 & 16.23 & $8: 00$ & -0.01079 & 0.00002 & 14.97 & $16: 00$ & 0.00276 & 0.01603 & 26.07 \\
$0: 30$ & 0.00539 & 0.00001 & 15.88 & $8: 30$ & -0.01889 & -0.00536 & 15.48 & $16: 30$ & -0.00263 & 0.01334 & 26.14 \\
$1: 00$ & 0.00806 & 0.00008 & 15.47 & $9: 00$ & -0.02426 & 0.00538 & 16.45 & $17: 00$ & -0.00802 & 0.01064 & 24.91 \\
$1: 30$ & 0.00266 & 0.00009 & 15.06 & $9: 30$ & -0.02150 & 0.02142 & 18.17 & $17: 30$ & -0.01072 & 0.00525 & 24.21 \\
2:00 & 0.00535 & 0.00011 & 14.9 & $10: 00$ & -0.01072 & 0.03760 & 19.85 & $18: 00$ & -0.01072 & -0.00014 & 22.68 \\
2:30 & 0.00535 & 0.00281 & 14.49 & $10: 30$ & 0.01085 & 0.03758 & 21.38 & $18: 30$ & -0.00802 & -0.00553 & 21.92 \\
$3: 00$ & 0.00804 & 0.00281 & 14.33 & $11: 00$ & 0.01359 & 0.03207 & 22.3 & $19: 00$ & -0.00802 & -0.00553 & 21.05 \\
$3: 30$ & 0.00804 & 0.00281 & 14.06 & $11: 30$ & 0.01364 & 0.02655 & 23.41 & $19: 30$ & -0.00263 & -0.00283 & 21.02 \\
$4: 00$ & 0.00804 & 0.00281 & 14.09 & $12: 00$ & 0.01095 & 0.02116 & 23.86 & $20: 00$ & -0.00533 & -0.00014 & 20.91 \\
$4: 30$ & 0.00804 & 0.00011 & 13.92 & $12: 30$ & 0.01364 & 0.02116 & 24.21 & $20: 30$ & -0.00266 & -0.00007 & 20.56 \\
$5: 00$ & 0.00535 & 0.00550 & 13.91 & $13: 00$ & 0.01364 & 0.02386 & 25.05 & $21: 00$ & -0.00269 & -0.00001 & 19.85 \\
$5: 30$ & 0.00804 & 0.00550 & 13.75 & $13: 30$ & 0.01092 & 0.02123 & 25.64 & $21: 30$ & -0.00269 & -0.00001 & 19.55 \\
$6: 00$ & 0.00535 & 0.00281 & 13.55 & $14: 00$ & 0.01090 & 0.01860 & 24.77 & $22: 00$ & -0.00269 & -0.00001 & 18.96 \\
$6: 30$ & 0.00265 & 0.00281 & 13.56 & $14: 30$ & 0.00820 & 0.01591 & 25.65 & $22: 30$ & -0.00269 & -0.00001 & 18.59 \\
$7: 00$ & -0.00275 & 0.00011 & 13.68 & $15: 00$ & 0.00277 & 0.01870 & 25.04 & $23: 00$ & 0.00001 & -0.00271 & 18.11 \\
$7: 30$ & -0.00544 & -0.00259 & 14.26 & $15: 30$ & 0.00276 & 0.01603 & 26.06 & $23: 30$ & 0.00270 & -0.00001 & 17.67 \\
\hline
\end{tabular}
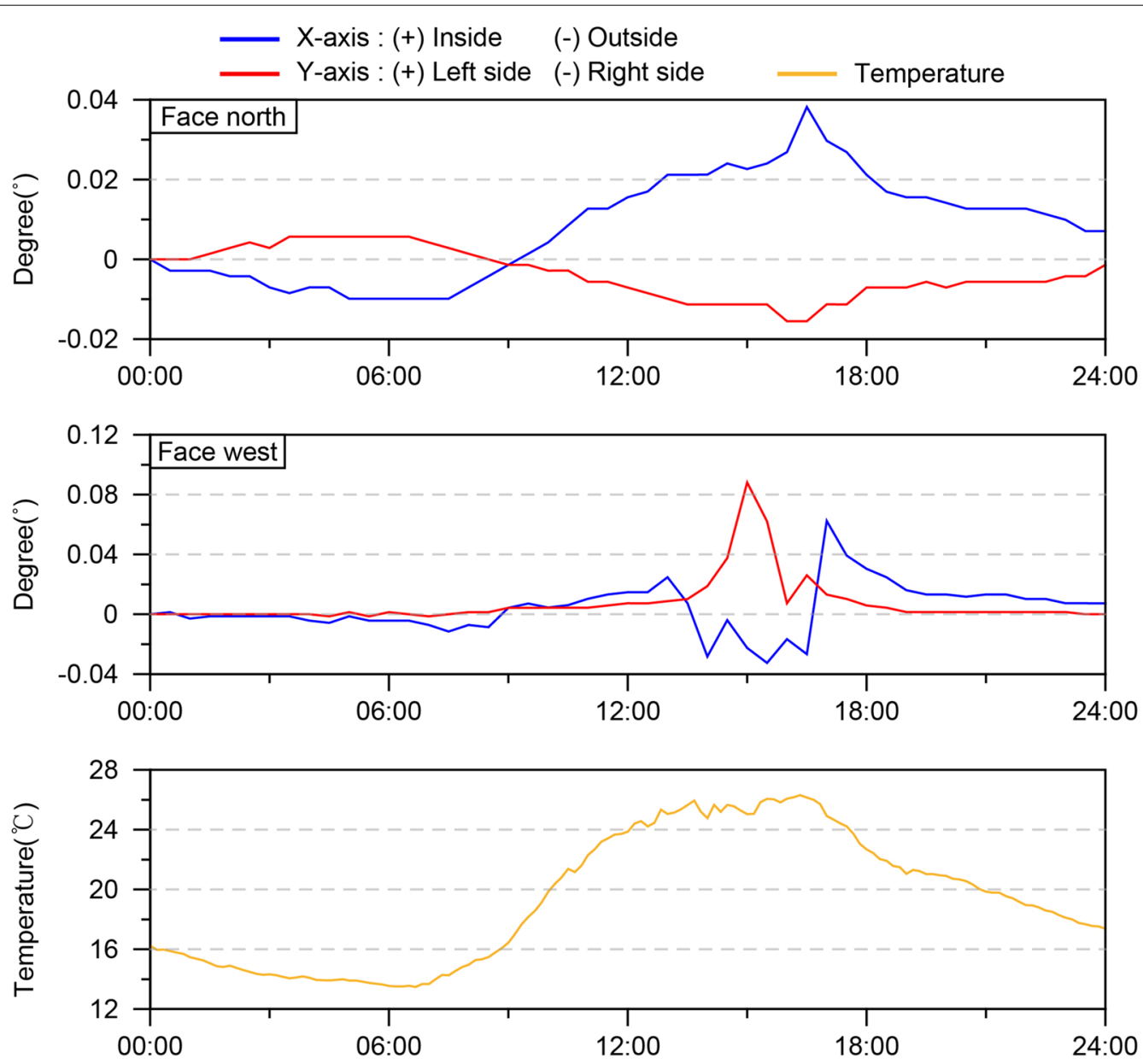

Fig. 8 Diagram showing the daily behavior as time series on some sensors of north and west faces in the ramparts 
temperature change first, the temperature begins to increase at about 6 a.m. when the sun rises and reaches the maximum around 2 p.m. The maximum temperature is maintained until about 4 p.m., from which the temperature starts to drop and continues to fall until sunrise on the following day.

Most of the sensors observed gradual movements as the temperature began to go up after sunrise and, after 4 p.m., showed a patterns in which they return to the state prior to the behavior change starts to occur. Although the temperature continued to drop until sunrise on the next day, the ramparts showed almost no movement after 8 p.m. and maintained a stable state.

However, the breadths of change and the main hours of movement slightly vary depending on the direction ramparts are facing. The monitoring sensors currently installed to face west, south and north, and those that face north and south demonstrate movements that are extremely similar to the temperature change. The ramparts that face west display stable behavior changes until the noon but, after this point until sunset, drastic behavior changes are observed. The fine movements detected by monitoring sensors attached on the ramparts can be interpreted to be mainly driven by expansion and contraction of the stones due to the thermoelastic coefficient depending on the temperature change and, subsequently, influenced by direct sunlight, which changes according to the sun's diurnal motion.

Behavior changes by the time series can be clearly seen once they are shown on a one-dimensional graph but difficulties exist in visually checking real behavior changes of the ramparts. If the results of monitoring from clinometer sensors are displayed on a two-dimensional coordinate system, the route of movement can be tracked, and there are cases of applying this method to, for instance, the Leaning Tower of Pisa in Italy and Big Ben of England in order to analyze their movements [21-24].

Showing the movements of the Gongsanseong Fortress on a two-dimensional plane, we see that movements as minutes occur at sunrise and behavior changes progress in a rotating form (Fig. 9). But it is also confirmed that the ramparts do not perfectly return their original positions after $24 \mathrm{~h}$, which means that slight differences occur. Such differences accumulate every day at all measuring points to make the rocks lean to a certain direction or produce gaps in between, and huge changes are detected in some sections. The direction to which stones move varies depending on the ramparts where sensors are attached, and some of them rotate in the clockwise direction while others rotate counterclockwise. To explore the factors that influence the direction of rotation, the data was compared with various morphological

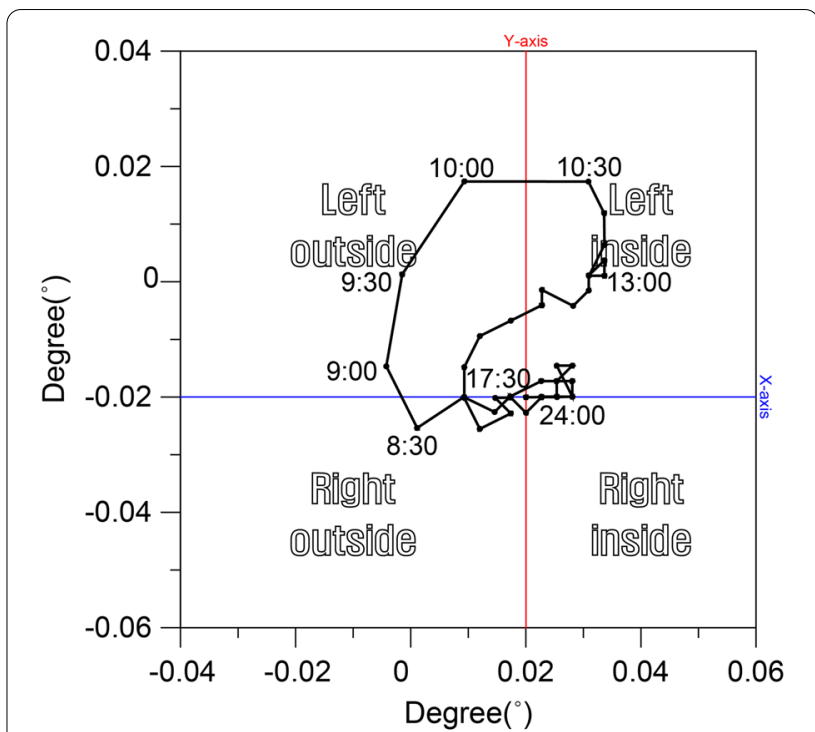

Fig. 9 Diagram showing the daily behavior in two dimensions on one sensor of typical movement on representative stones in the rampart

characteristics of the ramparts but no particular correlation was found.

\section{Annual changes}

Changes in minute daily movements produced by the sun's diurnal motion and temperature changes are repeated in a 24-h cycle and, as the microscale behavior changes are accumulated, a structural deformation occurs throughout the ramparts. To check the ramparts' movements and behavior changes over a 1-year cycle, 3 to 5 years of measurement data was shown in the form of a distribution graph on a two-dimensional plane. The number of measured data sets accumulated in a single sensor over a year is over 50,000 and, as it may be difficult to accurately understand the behavior due to an excessive volume of data, movements during a month were shown on a graph together at 12 a.m. on the first of every month to check the general trend.

As a result, we were able to classify behavior changes of the Gongsanseong Fortress into reversible changes and irreversible changes based on the reversibility of the change. Irreversible changes can then be subdivided into the predictable type and unpredictable type depending on the degree of predictability (Fig. 10). First, the reversible change type vibrates with periodicity centered on the origin of measurement and forms points of inflection during summer and winter each year.

This is the outcome to which the ramparts' thermoelastic behavior due to annual temperature changes is reflected, and it can be interpreted as that the ramparts 


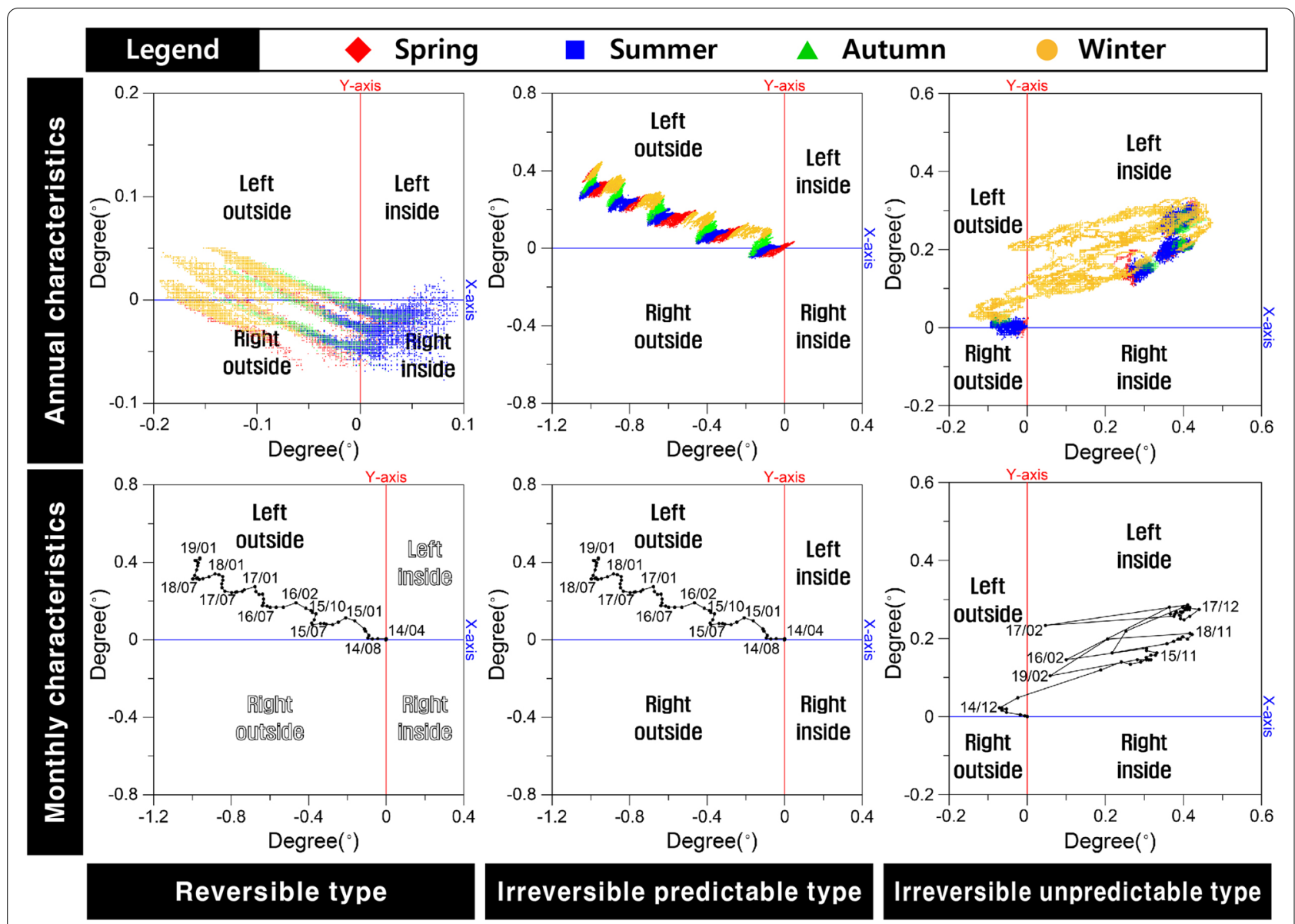

Fig. 10 Annual changes and monthly behavior characteristics on sensors of representative stones as types in the ramparts

retain structural restoring force. However, the ramparts do not perfectly return to the original state after a 1-year period and, instead, their slopes or distances slightly change to a certain direction. The magnitudes of changes generated are very similar from 1 year to the next, and the changes are continuously repeated without any change in the direction.

Among the irreversible change types, the predictable type has points of inflection during summer and winter, and allows to observe the progress of behavior changes with periodicity but also shows a pattern of slowly drifting away from the origin of measurement, causing the ramparts to move. The general form of behavior changes is very much standardized, and the same pattern repeatedly occurs every year so future trends of the changes can be projected approximately.

The direction to which an irreversible behavior proceeds does not change but, rather, continues to be maintained but the amount of change varies depending on the year measured. It was confirmed that periods during which characteristically significant changes occurred vary from one sensor to another, which may possibly be an effect of external factors such as the ground, structure and underground water near the ramparts rather than yearly differences in the weather environment.

Lastly, the unpredictable type of irreversible changes continuously produces irreversible structural deformations on the ramparts and no specific periodicity and regularity are observed, which makes it impossible to predict future behavior trends. This type ramprats tend to exhibit stable and predictable movements in spring, summer and fall but, during winter, these ramparts commonly show abnormal behaviors as the direction and amount of increase of behaviors fluctuate frequently. The fact that abnormal behaviors only occur in the wintertime is believed to be due to moisture remaining inside the ramparts that, as it goes through a process of freezing and melting and changes the volume, therefore, directly affects the structural deformation. 


\section{Environmental effects}

Most monitoring sensors were affected by temperature changes the most, and the effect of direct sunlight was detected principally by the direction. To check the effect of humidity, rainfall, wind direction and speed in addition to temperature, a comparative analysis was conducted with environmental measurement results, and it has been confirmed that the occurrence of rainfall and behavior changes coincide on some sensors (Fig. 11). However, not all the ramparts exhibited movements during rainfall, and behavior changes were only displayed in case of precipitation greater than a certain level.

The amount of precipitation needed for the behavior to occur varies from one rampart to the next and, on some sensors, movements of ramparts were observed even for a small amount of rainfall that lasts a long period of time. This points to the possibility of the behaviors affected not only by the rainfall taking place in an instant but also by the percentage of water content in the soil, which supports the ramparts.

Moreover, in order to check the effect of the vibrations caused by an earthquake, the time at which the earthquake took place and the changes in microscale behaviors were examined. Large-scale earthquakes happened in Gyeongju and Pohang, cities about $200 \mathrm{~km}$ away from the Gongsanseong Fortress in 2016 and 2017 in the period during the monitoring. Both earthquakes were in the magnitude of 5.0 with the maximum earthquake intensity over 8 , and large vibrations in the earthquake intensity size of 5 were detected in the Gongsanseong area as well. Behavior changes of the ramparts before and after the time at which the earthquakes occurred were compared by referring to the Korean earthquake observation data but no specific changes were identified.

This may have stemmed from the fact that the epicenters were located too far away and, thus, the energy delivered to the ramparts was not enough to cause any structural deformation. Also, the measurement cycles are set at 10- to 30-min intervals so, if the ramparts are restored immediately after behaviors caused by the earthquakes occur, it is impossible to detect them through sensors. Therefore, it has been revealed that the instantaneous movements caused by the earthquakes failed to reach over the structural critical point of the ramparts and, thus, no permanent deformations took place.

\section{Results and discussion}

Morphological characteristics and damage distributions

In this research, construction types were classified on the bases of morphological characteristics that can be observed on the ramparts, and they are subdivided into 9 types. The ramparts of an identical construction type

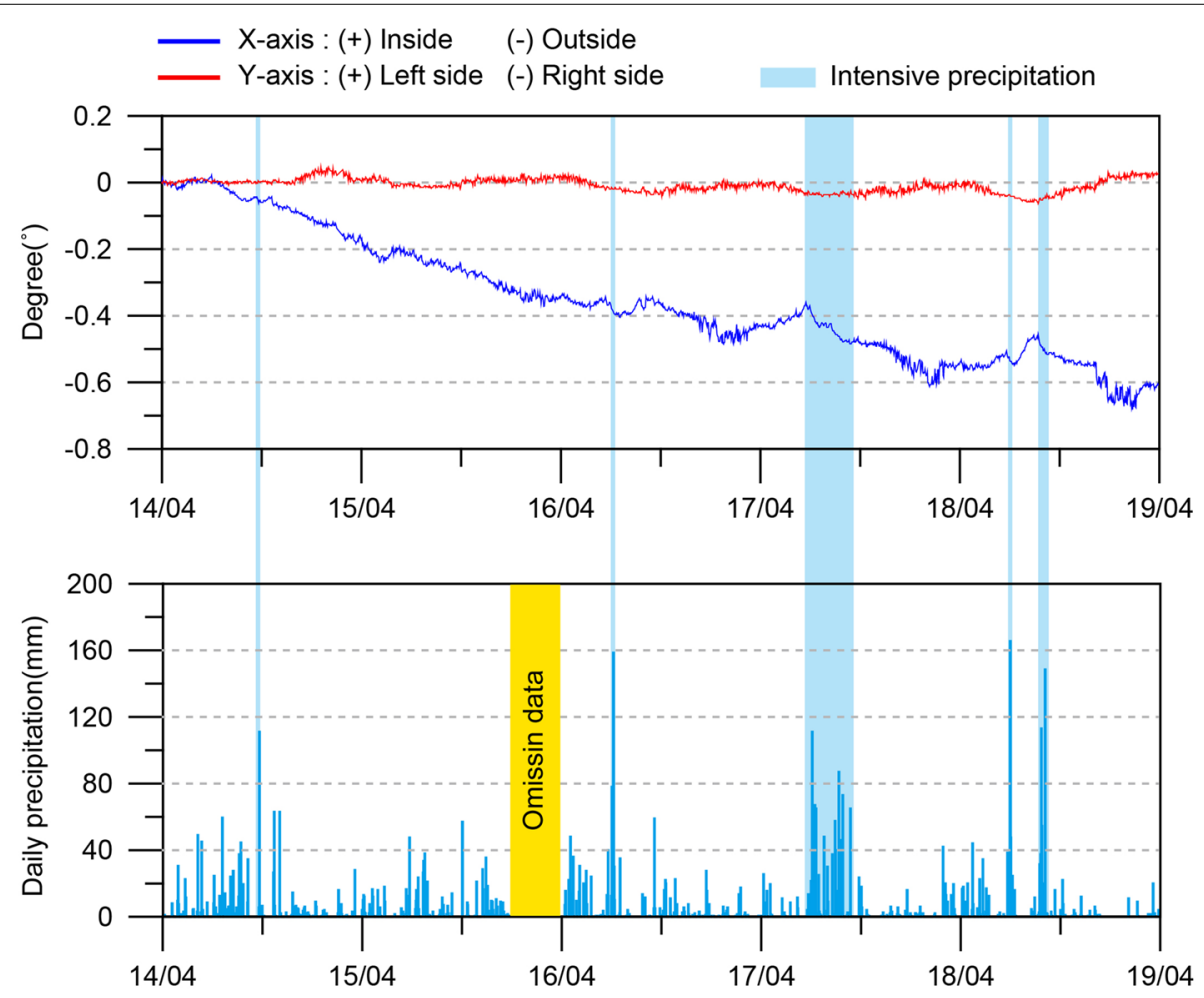

Fig. 11 Diagram showing the representative environmental movement variation of the rampart 
are expected to retain a similar level of structural stability and, when they are affected by the external environment, they are likely to experience damages by a similar mechanism. So, if the correlation between construction types and damages on the ramparts is interpreted, it is possible to obtain advance information on additional damages that may occur in the future.

Also, the classified construction types and the locations on the ramparts where structural deformations have occurred were overlapped to examine the distribution pattern (Fig. 3). First, many of the damaged sections in the Gongsanseong Fortress are located on northern slopes whereas the distribution of damaged ramparts is shown to be reduced on southern slopes. Among the different construction types, the most distributed type is type II, and the highest share of damaged ramparts compared to the length is shown in type I (Table 3).

Type I characteristically constructs stones in an irregular way without applying any particular technique, and the general condition of stones structured is poor, which leads to weak stability. On the other hand, almost no structural deformations are observed on type III ramparts for which restoration records exist and standardized stones were used. In addition to the fact that they have been restored in relatively recent times, it is influenced by the strong structural resistance as processed stones were used and constructed to match the joints.

Even if the same external force is exerted, the ramparts of type I to which no particular architectural technique was applied have difficulties in structurally resisting such a force so structural deformations may proceed more quickly. The ramparts that collapsed in 2013 correspond to type I and it is possible that, if a similar magnitude of

Table 3 Summary on deterioration ratio by construction types in the fortress

\begin{tabular}{lccc}
\hline $\begin{array}{l}\text { Construction } \\
\text { type }\end{array}$ & $\begin{array}{l}\text { Length of } \\
\text { ramparts }(\mathbf{m})\end{array}$ & $\begin{array}{l}\text { Number of } \\
\text { damaged spots }\end{array}$ & $\begin{array}{l}\text { Deterioration } \\
\text { ratio }\end{array}$ \\
\hline $\begin{array}{l}\text { Type I } \\
\text { I-A }\end{array}$ & 169 & 11 & 15.4 \\
I-B & 16 & 1 & 15.8 \\
Type II & & & \\
II-A & 545 & 13 & 41.9 \\
II-B & 89 & 1 & 88.8 \\
Type III & & & \\
III-A & 238 & 2 & 119.2 \\
III-B & 224 & 2 & 112.1 \\
III-C & 87 & 2 & 43.6 \\
III-D & 136 & 1 & 136.4 \\
III-E & 420 & 8 & 52.5 \\
Total & 1925 & 41 & 47.0 \\
\hline
\end{tabular}

external force is exerted on other type I ramparts that exist at other locations, similar structural deformations may take place along the structurally vulnerable points. Thus, for stable management of the ramparts, they must be continuously monitored and the construction types and distribution of damaged ramparts need to be considered as a whole in order to set the priorities and cycle of monitoring.

\section{Construction types and microscale behaviors}

In this research, monitoring sensors were installed primarily on the ramparts where structural deformations are observed in order to check the ramparts' microscale behaviors, and most of these ramparts fall under type I or II. Behavior changes of the ramparts are classified based on reversibility and predictability, and it has been confirmed that most types of such behavior changes are not related to construction types. However, a different pattern of behavior changes compared to other construction types was observed in type III. Monitoring sensors were not installed on type III ramparts because almost no structural deformations occurred on such ramparts but the sensors are installed at 2 locations near the west gate, an entrance into the Gongsanseong Fortress, for the safety of the visitors.

A battlement was installed on the rampart near the entrance but, after the issue of structural stability of the rampart was raised due to the load of the battlement, it was dismantled in 2015. During the process of removing this load, haviors were detected on the ramparts, and different forms of movements were observed depending on the construction type (Fig. 12).

First, near the entrance, the rampart that was restored after the 2000s and corresponds to type III is located and, on the left of the entrance, the rampart classified as type I neighbors the type III rampart. Looking at the results of behavior measurement before and after the dismantling of the battlement, type I experienced a gradual behavior change over 2 weeks after the dismantling while type III showed brittle changes and a stable pattern immediately after the dismantling. Type I ramparts were built to align the external surfaces only without processing the stones and, thus, the contact faces between stones are irregular. So, in order to maintain a structural equilibrium along with a change in loads, each of the stones behaved independently to proceed stabilization.

On the other hand, type III ramparts processed the stones in a rectangular form and constructed to match the joints. The contact faces between the stones are also very broad. Thus, it can be interpreted as a phenomenon in which an entire the rampart behaves like a single continuum along with a load change and creates a 


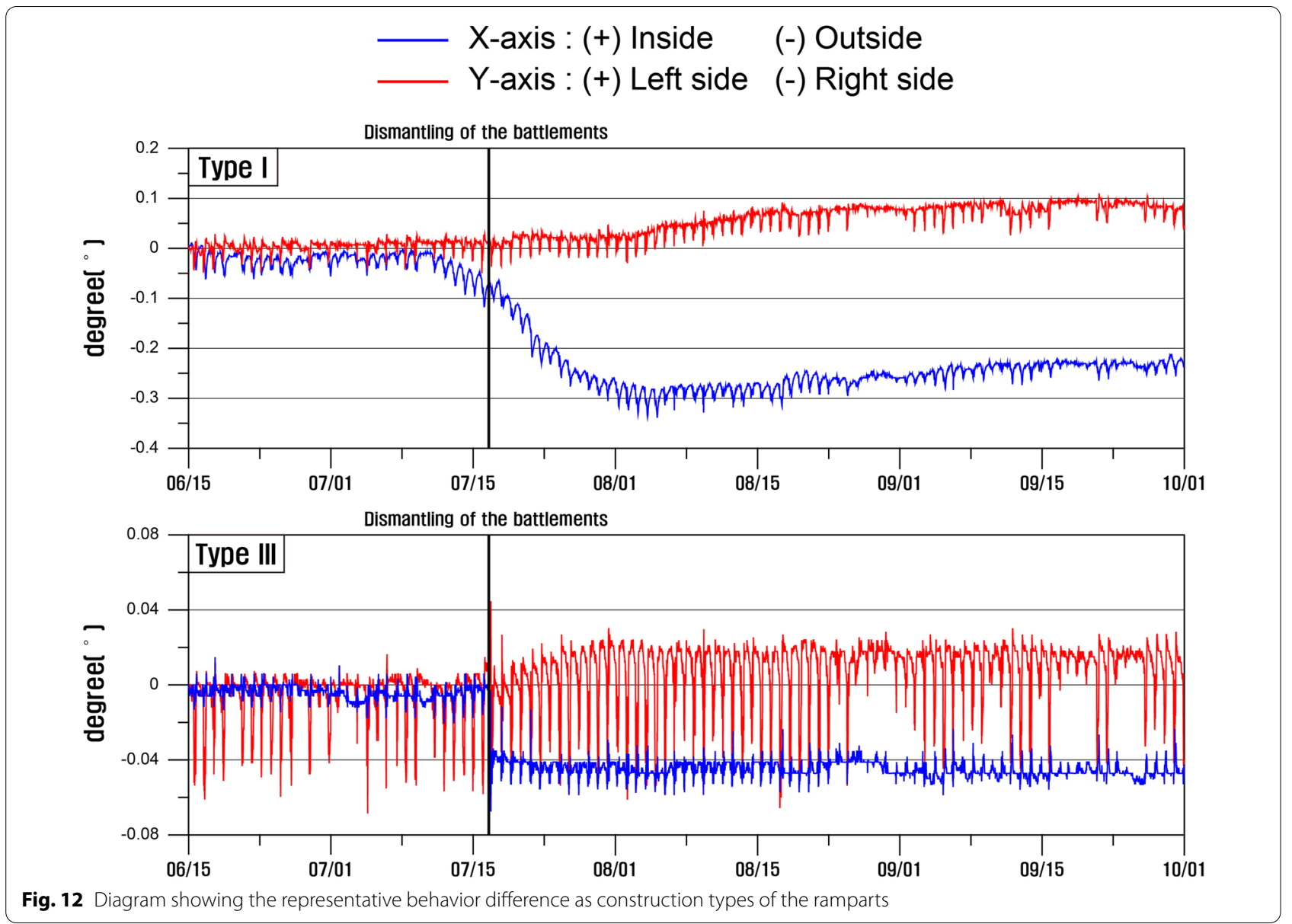

brittle change instantaneously before reaching stabilization. So, even in the same environment, different forms of behavior changes may be manifested depending on the construction type, and the effect of different behavior changes may occur as structural instability on the boundary between different construction types.

\section{Behavior and monitoring}

Evaluating the stability of structures based on measurement results has been widely performed in the field of architecture and structure, and mainly concentrated on national infrastructures such as bridges and dams. However, analyzing the monitoring of masonry structures cannot quantitatively investigate the effect that certain changes in slope and distance have on the entire structure, and there has not been any case of setting quantitative evaluation criteria based on the results of measurement of cultural heritage. In this study, the amount and direction of the behavior of the ramparts were quantitatively verified through measurement of the behavior, and three types were classified based on reversibility and predictability to review the ways of monitoring.
First, the ramparts with reversibility continuously produce a thermoelastic behavior due to temperature changes throughout a year, and behaviors in the form of rotation and vibration repeatedly appear. But the behaviors do not return perfectly to the original state, and deformations progress in a specific direction every year. It can be said that these sections of ramparts have a greater structural restoring force than other various external factors that can cause a deformation and, as it is relatively stable compared to other types, the continuity of reversibility must be monitored.

Among the sections that behave in the irreversible form, the ramparts of the predictable type continuously experience deformations and increased structural instability. Therefore, damages may occur on the ramparts from these sections because of structural deformations in the future and, once the critical point is exceeded, it is possible for a partial collapse to take place. So, among the monitoring sensors at the Gongsanseong Fortress, relative priorities must be set based on the amount of deformation to perform safety diagnoses of the ramparts and, if needed, implement reinforcements on the ramparts 
within the extent that sincerity and completeness of the cultural heritage are not defamed.

Lastly, the ramparts of the unpredictable type experience occurrence of abnormal behaviors, and the amount and direction of change of behaviors are periodically altered. It is believed that these sections are influenced by environmental factors and we need to figure out ways to eliminate the effect of such environmental elements. For the case of the Gongsanseong Fortress, it has been revealed that it is affected by the volume change caused by freezing and melting. Also, it may be the effect of underground water so an effect evaluation on this must be performed to control the remaining water inside the ramparts. In addition, the monitoring cycle needs to be set as short during periods that are intensively influenced by environmental factors to be able to monitor changes in stability of the fortress.

\section{Conclusions}

In this study, the status of damages on the Gongsanseong Fortress was investigated, and the types were classified based on morphological and material characteristics of the ramparts. Also, measuring sensors were attached at points where structural deformations have intensified to quantitatively analyze the minute movements of the ramparts. The results showed that damages on the ramparts are directly correlated with morphological and material characteristics, and different behavior measurement results were able to be obtained even for ramparts located in an identical environment depending on the shape and materials. Thus, the characteristics of the ramparts must be classified by base data for establishment of conservation and management schemes for cultural heritage of the ramparts. They also need to be placed into categories and different maintenance suitable for each of the categories must be applied.

Precision behavior measurement sensors were utilized to analyze microscale behaviors of the ramparts, and it has been confirmed that they are strongly affected by temperature changes and direct sunlight caused by the sun's diurnal motion. However, it was also found that certain sections are affected by environmental factors. The degree to which it is influenced by environmental factors has been confirmed to be far smaller than the size of thermoelastic behavior changes, and some of them were sealed by vibrations due to the thermoelastic behavior, which is why no clear pattern was detected. Changes caused by the sun's diurnal motions and the earth's revolution retain a specific periodicity in the form of high frequency and low frequency, respectively, and these are expected to be able to be eliminated through conversion and filtering of the time and frequency domains.
Morphological and material characteristics of the ramparts and environment measurement results were compared, and the existence of an interconnection has been confirmed. But certain characteristic behavior changes that cannot be explained by this have been observed, which may have been driven by other factors that could not be measured. A variety of elements such as geological features, ground, structure and underground water comprehensively influence architectural structures, and the measurement results are exhibited in a complex form in which individual effects are mixed.

Thus, for the ramparts on which irreversible changes have been detected based on the results of behavior measurements, priorities must be set through relative comparison of the number of behaviors, and, through precise safety diagnoses including geophysical prospecting, structural analyses and water table measurements, elements of instability must be clearly investigated. In setting of priorities for changes in risk of the ramparts, the results of behavior measurements will be able to be utilized with importance and, once a management system is established through long-term monitoring, it will be effectively utilized for long-term conservation and maintenance of cultural heritage.

\section{Abbreviations \\ IOT: Internet of Things; GNSS: Global navigation satellite system; CDMA: Code division multiple access; FDMA: Frequency division multiple access; TDMA: Time division multiple access. \\ Acknowledgements \\ This study was supported by the research grant of the Kongju National University in 2019}

\section{Authors' contributions}

All authors contributed to the planning, design of this article, performed the data acquisition and data analysis, and JHP wrote the manuscript and all authors revised it critically. All authors read and approved the final manuscript.

Funding

This work was financially supported by the Kongju National University.

Availability of data and materials

Not applicable.

\section{Declarations}

Competing interests

The authors declare that they have no competing interests.

Received: 14 February 2021 Accepted: 20 May 2021

Published online: 02 June 2021

\section{References}

1. D'Altri AM, Castellazzi G, de Miranda S. Collapse investigation of the Arquata del Tronto medieval fortress after the 2016 Central Italy seismic sequence. J Build Eng. 2018;18:245-51. 
2. Park JH, Lee $\mathrm{CH}$. Conservation status, construction type and stability considerations for fortress rampart in Hongjuupseong (Town rampart) of Hongseong, Korea. Korean J Cult Herit Stud. 2018;51:4-31.

3. Suh MC, Park EJ. Characteristics of subsurface movement and safety of the Songsanri tomb site of the Baekje dynasty using tiltmeter system. J Eng Geol. 1997;7:191-205.

4. Jo YH, Lee $\mathrm{CH}$. Behavioral monitoring and stability evaluation of Korean stone pagoda in Magoksa Temple using tiltmeter sensor. Int J Appl Eng Res. 2014:9:14659-68.

5. Agapiou A, Lysandrou V, Alexakis DD, Themistocleous K, Cuca B, Argyriou A, Sarris A, Hadjimitsis DG. Cultural heritage management and monitoring using remote sensing data and GIS: the case study of Paphos area, Cyprus. Comput Environ Urban Syst. 2015;54:230-9.

6. Lorenzoni F, Casarin F, Caldon M, Islami K, Modena C. Uncertainty quantification in structural health monitoring: applications on cultural heritage buildings. Mech Syst Signal Process. 2016;66-67:268-81.

7. Varas-Muriel MJ, Fort R. Microclimatic monitoring in an historic church fitted with modern heating: implications for the preventive conservation of its cultural heritage. Build Environ. 2018;145:290-307.

8. Verstrynge E, Wilder K, Drougkas A, Voet E, Van Balen K, Wevers M. Crack monitoring in historical masonry with distributed strain and acoustic emission sensing techniques. Constr Build Mater. 2018;162:898-907.

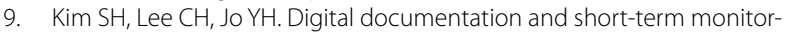
ing on original rampart wall of the Gyejoksanseong Fortress in Daejeon. Korea Econ Environ Geol. 2019;52:169-88.

10. Gentile C, Guidobaldi M, Saisi A. One-year dynamic monitoring of a historic tower: damage detection under changing environment. Meccanica. 2016;51:2873-89.

11. Basto C, Pelà L, Chacón R. Open-source digital technologies for low-cost monitoring of historical constructions. J Cult Herit. 2017;25:31-40.

12. Hester J, Prabhu S, Atamturktur S, Sorber J. Remote and wireless long-term vibration monitoring of historic monuments. Procedia Eng. 2017;199:3302-7.

13. Saisi A, Gentile C, Ruccolo A. Static and dynamic monitoring of a cultural heritage bell-tower in Monza, Italy. Procedia Eng. 2017;199:3356-61.

14. Mesquita E, Arêde A, Pinto N, Antunes P, Varum H. Long-term monitoring of a damaged historic structure using a wireless sensor network. Eng Struct. 2018;161:108-17.

15. Perles A, Pérez-Marín E, Mercado R, Segrelles JD, Blanquer I, Zarzo M, Garcia-Diego FJ. An energy-efficient internet of things (loT) architecture for preventive conservation of cultural heritage. Future Gener Comput Syst. 2018;81:566-81.
16. Wang Y, Dai X, Jung JJ, Choi C. Performance analysis of smart cultural heritage protection oriented wireless networks. Future Gener Comput Syst. 2018;81:593-600.

17. Addabbo T, Fort A, Mugnaini M, Panzardi E, Pozzebon A. A city-scale loT architecture for monumental structures monitoring. Measurement. 2019;131:349-57

18. Sainz C, Rábago D, Celaya S, Fernández E, Quindós J, Quindós L, Fernán$\operatorname{dez}$ A, Fuente I, Arteche JL, Quindós LS. Continuous monitoring of radon gas as a tool to understand air dynamics in the cave of Altamira (Cantabria, Spain). Sci Total Environ. 2018;624:416-23.

19. Guirado E, Ramos-López D, Maldonado AD, Moreno-Balcázar JJ, Calaforra JM. Modeling carbon dioxide for show cave conservation. J Nat Conserv. 2019;49:76-84.

20. Kim SH, Lee $\mathrm{CH}$. Interpretation on internal microclimatic characteristics and thermal environment stability of the Royal Tombs at Songsanri in Gongju. Korea J Conserv Sci. 2019;35:99-115.

21. Burland JB, Hancock RJR. Underground car park at the House of Com mons, London: geotechnical aspects. Struct Eng. 1977;55:87-100.

22. Burland JB, Viggiani C. Osservazioni sul comportamento della Torre di Pisa. Rivista Italiana di Geotecnica. 1994;28:179-200.

23. Burland JB, Jamiolkowski M, Viggiani C. Leaning tower of Pisa: behaviour after stabilization operations. Int J Geoeng Case Hist. 2009;1:156-69.

24. Standing JR, Burland JB. Unexpected tunnelling volume losses in the Westminster area, London. Geotechnique. 2006;56:11-26.

25. Doebling SW, Farrar CR, Prime MB, Shevitz DW. Damage identification and health monitoring of structural and mechanical systems from changes in their vibration characteristics: a literature review. Los Alamos National Laboratory report. 1996;LA-13070-MS: 1-136.

26. Park JH, Yang KK, Park CU, Jo YH, Lee CH. Conservation status and behaviour monitoring system of Gongsanseong Fortress wall in Gongju, Korea. In: Proceedings of the 13th international congress on the deterioration and conservation of stone, vol. 1; 2016. p. 445-50.

27. Park JH. A study on the conservative management systems based on nondestructive precise diagnosis, auto measuring monitoring and geographic information systems of the Gongsanseong Foretress wall in Gongju, Korea. Doctorate, The Kongju National University, Gongju, Republic of Korea; 2020. p. 1-295.

\section{Publisher's Note}

Springer Nature remains neutral with regard to jurisdictional claims in published maps and institutional affiliations.

\section{Submit your manuscript to a SpringerOpen ${ }^{\circ}$ journal and benefit from:}

- Convenient online submission

- Rigorous peer review

- Open access: articles freely available online

- High visibility within the field

Retaining the copyright to your article

Submit your next manuscript at springeropen.com 